\title{
Evaluation of the Electrochemically Active Surface Area of Microelectrodes by Capacitive and Faradaic Currents
}

Alina Sekretareva, Mikhail Vagin, Anton Volkov, Igor Zozoulenko and Mats Eriksson

The self-archived postprint version of this journal article is available at Linköping University Institutional Repository (DiVA):

http://urn.kb.se/resolve?urn=urn:nbn:se:liu:diva-161170

N.B.: When citing this work, cite the original publication.

Sekretareva, A., Vagin, M., Volkov, A., Zozoulenko, I., Eriksson, M., (2019), Evaluation of the Electrochemically Active Surface Area of Microelectrodes by Capacitive and Faradaic Currents, CHEMELECTROCHEM, 6(17), 4411-4417. https://doi.org/10.1002/celc.201900989

Original publication available at:

https://doi.org/10.1002/celc.201900989

Copyright: Wiley

http://eu.wiley.com/WileyCDA/ 


\title{
Evaluation of the electrochemically active surface area of
}

\section{microelectrodes by capacitive and faradaic currents}

\author{
Alina N. Sekretaryova ${ }^{1,2}$, Mikhail Yu. Vagin ${ }^{1,3 *}$, Anton V. Volkov ${ }^{3}$, Igor V. Zozoulenko ${ }^{3}$, Mats \\ Eriksson $^{1}$ \\ ${ }^{1}$ Department of Physics, Chemistry and Biology, Linköping University, 58183, Linköping, \\ Sweden \\ ${ }^{2}$ Department of Chemistry - Ångström, Uppsala University, Lägerhyddsvägen 1, 75120, \\ Uppsala, Sweden \\ ${ }^{3}$ Laboratory of Organic Electronics, Department of Science and Technology, Linköping \\ University, 60174, Norrköping, Sweden \\ *Corresponding author \\ Mikhail Yu. Vagin \\ Email: mikhail.vagin@liu.se \\ Phone: $+46(0) 702753087$
}

\begin{abstract}
Two experimental methods to estimate the electrochemically active surface area (EASA) of microelectrodes are investigated. One method is based on electrocapacitive measurements and depends significantly on the surface roughness as well as on other parameters. The other method is based on faradaic current measurements and depends on the geometric surface area. The experimental results are supplemented with numerical modeling of electrodes with different surface roughness. A systematic study reveals a strong influence of the scale and arrangement of the surface roughness, the measurement potential and the electrolyte concentration on the EASA of microelectrodes estimated from the electrocapacitive measurements. The results show that
\end{abstract}


electrocapacitive measurements should not be used to estimate the faradaic EASA of microelectrodes with a non-negligible surface roughness.

Keywords: electrochemically active surface area, microelectrode, microband, roughness, capacitive current, faradaic current, numerical modeling.

\section{Introduction}

Small-sized electrodes with dimensions of tens of micrometers or less, possessing a convergent diffusion, referred to as microelectrodes, [1] are of significance within the field of modern electrochemistry. Due to their unique electrochemical properties, such as high current densities resulting from enhanced mass transport, high signal-to-noise ratios and reduced solution resistance, $[2,3]$ microelectrodes are versatile tools in electron transfer kinetics measurements and of major interest for electroanalysis and scanning electrochemical microscopy. Recently, microelectrodes have been widely applied for in-vivo studies of chemical events in biological systems such as tissues, biological cells or even whole animals. [4]

One of the distinguishing features of a microelectrode is the small current, typically in the $\mathrm{pA}$ range, combined with a high current density due to the small electrode size.[5] Therefore, even small errors in determination of the real surface area of the microelectrode has a large impact on current density calculations. Since electrode reaction rates and most double layer parameters are dependent on the area of the interface, knowledge of the real surface area of an electrode is needed for correct calculations of various parameters of electrochemical processes and comparison of experimental data with theories and between different materials and laboratories.[6]

The surface area available for a certain electrochemical process, referred to as the electrochemically active surface area (EASA), is usually different from the geometric surface area, with their ratio defined as the "electrochemical roughness", $f_{r}\left(f_{r}=\right.$ EASA/geometric surface area). [7] The roughness of the electrode surface causes a heterogeneity of the surface energy states. This heterogeneity should appear in different ways in the case of electrode polarization without any 
faradaic process and in the case of the electric charge passage through the phase boundary. [8] This effect is related to the different values of the EASA of electrodes with heterogeneous energy states in different electrode processes.

Several investigations have been published on different methods of normalizing experimental data to the EASA for solid macroelectrodes. $[6,7,9,10]$ It has been shown that the value of the real surface area depends on the method used. $[6,8]$ Thus, it should be measured under conditions closely related to the experimental situation where the electrode is to be applied. [9] Methods based on measurements of the double layer capacitance using the Gouy-Chapman theory are most commonly used for the EASA estimation of macroelectrodes. [11-13] However, the differential capacitance of the electrode depends nonlinearly on applied potential, electrolyte concentration and electrode roughness. $[14,15]$ Due to the non-linear behavior of the double layer capacitance, the value of the EASA estimated from capacitance measurements is accompanied by significant errors.

In the case of microelectrodes, there are many theories describing the current response dependence on the surface area and the shape of the microelectrode. However, most theories consider microelectrodes as a smooth, homogeneous surface without any roughness. [16-18] Effects of surface roughness and heterogeneity have been examined only for time-dependent situations. Aoki at al. [19] propose a method for determination of the surface area of disk and hemi-spherical microelectrodes using Saito's [20] equation from steady-state diffusion controlled currents. Evaluation of real microelectrode areas using linear diffusion currents can be done by using highly viscous electrolytes [21] or short time domains [22]. For gold microelectrodes, it is possible to estimate the real surface area exposed to the electrolyte by labeling the gold surface chemically with a redox-tagged alkanethiol. [23]

In this work, we consider the effect of surface roughness on the EASA of microelectrodes under conditions of different electrode processes. The dependence of the value of the EASA on the electrode process, the measurement potential and the electrolyte concentration is demonstrated 
using microelectrodes of two different geometries, microdisks and microband arrays, and different electrode materials, gold and printed carbon, respectively, by both experiment and numerical modeling.

\section{Experimental}

\subsection{Chemicals}

All inorganic salts were obtained at the highest purity from Sigma Aldrich (Sweden). Experiments were carried out with Milli-Q water from a Millipore Milli-Q system.

\subsection{Apparatus}

An Autolab type III potentiostat (Autolab, EcoChemie, Netherlands) was used for electrochemical measurements. Cyclic voltammetry and chronoamperometry were performed in a three-electrode cell with a $\mathrm{Ag} / \mathrm{AgCl}$ electrode in $3 \mathrm{M} \mathrm{KCl}$ or a standard calomel electrode (SCE) as a reference electrode and a platinum wire as a counter electrode. The electrochemical cell was kept in a Faraday cage.

Gold macrodisk electrodes with a diameter of $2 \mathrm{~mm}$, gold microdisk electrodes (AuME) with a diameter of $12.5 \mu \mathrm{m}$ (CHI101 and CHI105, respectively, $\mathrm{CH}$ Instruments), screen-printed graphite macrodisk electrodes with a diameter of $1.8 \mathrm{~mm}$ (Rusens LTD, Russia) and graphite microband arrays[24] were used as working electrodes.

The gold macroelectrode was successively polished with alumina powders $(1.0,0.3$ and $0.05 \mu \mathrm{m})$ followed by ultrasonication in distilled water. Then electrochemical pretreatment was performed by 20 successive scans between gold redox potentials (from $0 \mathrm{~V}$ to $1.5 \mathrm{~V}$ ) in $0.5 \mathrm{M} \mathrm{H}_{2} \mathrm{SO}_{4}$ aqueous solution, at $100 \mathrm{mV} \mathrm{s}$. After that the electrode was rinsed with water.

Before each use, AuMEs were polished with 0.3 and $0.05 \mu \mathrm{m} \mathrm{Al}_{2} \mathrm{O}_{3}$ powder in lemniscate-shaped motions and rinsed thoroughly with Milli-Q water. To obtain electrodes with different roughness, polishing in different directions with $0.05 \mu \mathrm{m} \mathrm{Al}_{2} \mathrm{O}_{3}$ powder was performed: unidirectional linear, forward-backward linear and lemniscate-shaped polishing. 
The graphite microband arrays were screen printed as described previously (Fig. 1A). [24] The graphite screen-printed microband arrays were used as working electrodes after cutting normal to the substrate surface with scissors. The microband working electrode was then connected to the potentiostat using a conductive adhesive tape and crocodile clips. Recovery of the microband electrode arrays was achieved by cutting a small portion of the working electrode in order to produce a new graphite surface. Arrays of 10 microbands with lengths of $0.04,0.05,0.06,0.08$, $0.1,0.12,0.14$ and $0.15 \mathrm{~cm}$ were used.

When data is presented with mean value and deviation we have used the Student's t-distribution at $95 \%$ confidence and 5 samples.

\section{Theoretical model of the rough microband electrodes}

The problem of diffusion to the three-dimensional microband electrode can be treated as a twodimensional problem when the microband length, $l$, is much larger than its width $w$. [20]. Thus, only a 2D 'slice' of the electrode (Fig. 1B) needs to be considered using the Cartesian coordinate system. [25] The chronoamperometric response of microband electrodes with flat and rough electrode surfaces within the diffusion domain [26] was simulated using a finite element method[25] for the 2D 'slice' of the electrode system. The maximum extent of the diffusion layer over the duration of the simulation $R_{D}$ was estimated as:

$$
R_{D}=6 \sqrt{2 D t_{\max }}
$$

where $D$ is the diffusion coefficient of the reduced form of the redox probe $\left(6.7 \times 10^{-6} \mathrm{~cm}^{2} \mathrm{~s}^{-1}\right)$ [27] and $t_{\max }$ is the time of the chronoamperometric experiment $(0.3 \mathrm{~s})$. Faradaic currents for each single microband in the array are assumed to be equal. Thus, the average faradaic current for a single microband could be obtained by the integration across the line over the electrode boundary in ZY cross section:

$I=-F l \int_{S} D \vec{n} \vec{\nabla} C_{R} d s$ 
where $F$ is the Faraday constant, $\vec{n}$ is a normal vector and $C_{R}$ is the concentrations of the reduced form of the redox probe.

The roughness of the microband electrode in the cross-section was modeled by:

$z=a \cos ^{2}(\pi b y / w)$

or by:

$z=a \sin (2 \pi b y / w)$

where $a$ is the characteristic scale of the roughness $(0.25 \mu \mathrm{m}, 0.5 \mu \mathrm{m}$ and $2 \mu \mathrm{m}$ were used $), b$ is a geometric parameter illustrating the number of periods within the microband electrode boundary (e.g. $b=5$ for Fig. 1B), $w$ is the microband width estimated from optical measurements $(7 \mu \mathrm{m})[24]$ and $y=\left(-\frac{w}{2}, \frac{w}{2}\right)$.

\section{Results and discussion}

\subsection{Capacitive electrode process}

Measurements of the double layer capacitance from cyclic voltammetry experiments in a solution containing only supporting electrolyte, where no faradaic current was present, [28] was used for estimations of the capacitive EASAs of the microelectrodes. Typical voltammograms recorded at the screen-printed graphite microband electrode array $(0.15 \mathrm{~cm}$ microband length $)$ and the graphite disk electrode (diam. $1.8 \mathrm{~mm}$ ) with different scan rates are shown in Fig. 2A and 2B, respectively. An increase of the capacitive current with increasing scan rate is observed for all electrodes, as expected. The capacitive current contribution, $i_{c}$, to the anodic current at potentials far enough from the switching potentials increases with scan rate: [22]

$i_{c}=v A C_{d}$

where $v$ is the scan rate $\left(\mathrm{V} \mathrm{s}^{-1}\right), A$ is the electrode surface area and $C_{d}$ is the specific double layer capacitance $\left(\mathrm{F} \mathrm{cm}^{-2}\right)$. Assuming equal specific capacitance of the double layer at the micro- and macro-dimensional electrodes, which are made of the same material, the ratio between the slopes of $i_{\mathrm{c}}$ vs $v$ plots (Fig. 2C and Fig. 2D) is equal to the ratio of the EASA available for formation of 
the electrical double layer. The ratios between the slopes of $i_{c}$ vs $v$ plots obtained for microband arrays of different geometries and the graphite disk electrode were calculated. Considering the electrochemical roughness, $f_{r}$, of the screen-printed macroelectrode to be around 0.8 , [3] the values of the microband capacitive EASAs were assessed (Fig. 4A, EASA Capacitive). The capacitive EASA increases approximately linearly with increasing microband length. The larger variation of the EASA values observed for the longer microbands illustrates a larger irreproducibility of the surface at larger electrode structures related to the roughness of the microband electrodes.

To demonstrate the challenge of EASA assessment from electrocapacitive data, impedance spectroscopy was utilized to estimate the capacitance of the electrical double layer formed at the screen-printed macroelectrode as the semicircle diameter formed by the impedance spectra plotted in complex capacitance coordinates (Inset in Fig. S1). The mapping with applied potential (Fig. S1) clearly illustrates a dependence of the double layer capacitance and therefore capacitive EASA on the potential for both concentrated and diluted electrolyte solutions. The potential dependence observed for the diluted electrolyte showed a minimum of the capacitive roughness at $0.55 \mathrm{~V}$, which, likely, corresponds to the potential of zero charge of the screen-printed macroelectrode, where the diffusive part of the electrical double layer is highly blurred by thermal motion. Due to the dense electrical double layer, the potential dependence is more monotonous in the concentrated electrolyte. The obtained data are in agreement with those of the extensive review by Grahame. [29] The spectra obtained for the microband arrays did not allow a reliable assessment of the EASA (data not shown) due to complex impedance phenomena on the microdimensional electrodes affected by a higher ohmic drop than on macroelectrodes. These experimental facts clearly demonstrate that EASA assessments from electrocapacitive measurements are uncertain. The same methodology was utilized for the assessment of the AuME EASA. Firstly, the EASA of a gold macroelectrode was assessed by the Trasatti-Petrii approach: [6]

$$
E A S A_{\text {Oxide }}=\frac{Q}{Q_{\text {ref }}}
$$


where $E A S A_{\text {Oxide }}$ is the surface area of the gold electrode assessed from the reduction of an oxide monolayer (Fig. S2), $Q$ is the charge needed to form the gold oxide monolayer and is calculated by an integration of the reduction peak (at $0.9 \mathrm{~V}$ in Fig. S2) and $Q_{r e f}\left(390 \mu \mathrm{C} \mathrm{cm}^{-2}\right)$ is a calibration factor for a polycrystalline gold electrode. The obtained $Q$ value was $20.45 \mu \mathrm{C}$. This gives an EASA Oxide of $5.24 \times 10^{-2} \mathrm{~cm}^{2}$ and a roughness factor of 1.7 , which is within the range of previously reported values. [30] Secondly, the EASA of the AuME was estimated from the ratio between the capacitive currents obtained at the gold macroelectrode and the AuME (Fig. S3). The values of the AuME EASA were modulated by polishing in different directions as described in section 2.2 (Fig. S4A) and assessed in electrolytes of different ionic strengths. The EASA was found to be (6 \pm $2) \times 10^{-6} \mathrm{~cm}^{2}$ in $10 \mathrm{mM} \mathrm{KNO}_{3}$ and $(2.4 \pm 1.4) \times 10^{-5} \mathrm{~cm}^{2}$ in $1 \mathrm{M} \mathrm{KNO}_{3}$. Compared with the geometrical area, $1.23 \times 10^{-6} \mathrm{~cm}^{2}$, a large variation of the electrochemical roughness, $3<f_{r}<30$, was thus observed.

The observed dependence of the EASA on the electrolyte concentration illustrate the interplay between the capacitances of the Helmholtz and the diffuse layers. According to the GouyChapman-Stern model of the electric double layer formed at the electrode surface in the electrolyte solution, the smaller of the two components govern the whole capacitance. The diffuse layer becomes denser in solution of higher electrolyte concentration yielding a smaller contribution. Being sensitive to the surface roughness and independent on the solution concentration, the capacitance of the Helmholtz layer therefore has a larger influence in the measurements in higher concentration of electrolyte. Both the surface roughness effect and the concentration effect lead to a higher double layer capacitance for the high concentration and the increased effect of the surface roughness also resulted in a higher variation of the EASA value in that case (Fig. 4B-C). A similar behavior was observed previously for Pt mesoporous electrodes,[31] but has, as far as we know, not been reported for microelectrodes.

\subsection{Faradaic electrode process}


Chronoamperometry was applied to calculate the EASA for the faradaic process. The electrodes were subjected to a potential step from conditions of no redox process to a potential of redox probe electrolysis. The obtained transients of the current densities for the screen-printed microband arrays are shown in Fig 3A. The chronoamperometric current at microband electrodes can be described by the equation derived by Aoki et al.: [17]

$$
i=n F C_{R} D l\left(\frac{w}{\sqrt{\pi D t}}+1\right)
$$

where $n$ is the number of transferred electrons per single redox reaction ( $n=1$ in this case) and $t$ is the time. The microband width was calculated from a plot of $i v s 1 / \sqrt{t}$ (Fig. 3B). By extrapolating the linear part to zero current, values of $w$ can be estimated with $D$ as the only parameter. The obtained values of the width of microbands with different lengths (Fig. S5) were used to calculate the surface area for each microband length, assuming that the error in the microband length determination is equal to the resolution achievable by the screen-printing method used $\left(1 \times 10^{-2} \mathrm{~cm}\right)$. The faradaic EASA of the microband electrode arrays obtained in this way for microband lengths of $0.04-0.15 \mathrm{~cm}$ is in the range $2.7 \times 10^{-4}-1.4 \times 10^{-3} \mathrm{~cm}^{2}$ (Fig. 4A). These values are in a similar range as the capacitive EASA but with much lower variation and the linear dependence on microband length is now much clearer. For comparison the geometric area was also calculated (Fig. 4A) based on a microband width of $7 \pm 1 \mu \mathrm{m}$, assessed by profilometry measurements and optical microscopy as reported previously. [24] The geometric and the faradaic EASAs agree quite well.

A similar approach was applied to calculate the EASA of the AuME (Fig. S4B). The current of a single disk microelectrode with radius $r_{0}$ can be described by:[5]

$$
i=n F A C_{R} \sqrt{\frac{D}{\pi t}}+4 n F C_{R} D r_{0}
$$

where $r_{0}$ is the radius of the disk microelectrode. For microelectrodes at longer times the process is dominated by convergent diffusion and the first term in eq. (8) becomes negligible. The steady- 
state current was used to calculate the electrode radius and subsequently the EASA for the AuME. The faradaic EASA for the microdisk electrode in $10 \mathrm{mM} \mathrm{KNO}_{3}$ was calculated to be $(0.88 \pm 0.10) \times 10^{-6} \mathrm{~cm}^{2}$ and in $1 \mathrm{M} \mathrm{KNO}_{3}(1.310 \pm 0.004) \times 10^{-6} \mathrm{~cm}^{2}$ (Fig. 4B and $4 \mathrm{C}$, respectively) The obtained values are close to each other and to the geometric surface area $(1.227 \pm 0.002) \times 10^{-}$ ${ }^{6} \mathrm{~cm}^{2}$. A similar increase of the faradaic EASA with increase in electrolyte ionic strength has previously been observed for mesoporous Pt structures. [31]

The values of the faradaic EASA are close to the geometric surface areas and have smaller deviations compared to the capacitive EASA for both electrode materials (Fig. 4B-C), illustrating a higher reliability of the faradaic approach compared to the assessment with the electrocapacitive process. The impact of the Helmholtz layer (i.e. the dense part of the electric double layer), crucially affected by the surface roughness and manifested in the concentrated electrolyte solution, results in larger values of the deviations of the EASA, which makes the electrocapacitive measurement strategy unreliable.

\subsection{Modeling of rough microelectrodes}

In order to explore the effect of roughness on the faradaic and capacitive processes at the microband electrode, chronoamperometric responses were modelled assuming metallic conductivity of the electrode for flat and rough microscale geometries of the electrode surface. A numerical chronoamperogram (Fig. 3B, dotted cyan curve) obtained via response modeling for a flat microband electrode with the width of $7 \mu \mathrm{m}$ is in good agreement with the analytical data obtained by eq. (7) for short times (Fig. 3B, black squares). The numerical response obtained for the rough microband electrode (Fig. 3B, dotted magenta curve) was fitted by eq. (7) yielding a microband width value of $7.61 \mu \mathrm{m}$, which is close to the value obtained for the flat geometry, which is in agreement with previous reports from Compton et al. [32, 33] The experimental chronoamperograms (Fig. 3B, solid lines) are characterized by lower currents than those obtained by the simulation (Fig. 3B, dotted lines). There may be several reasons for this discrepancy. Firstly, 
the lower currents might be due to the ohmic drop contributed by the resistance within the 'fingers' of the carbon microband array. The values of the ohmic drop estimated by impedance spectroscopy were around $1 \mathrm{k} \Omega$. Secondly, the experimentally observed kinetics of the faradaic process might be slower than theoretical due to the presence of binder/additives in the printed carbon composite. Thirdly, a lower than the nominal probe concentration might lead to the observation of smaller currents.

In order to carry out a systematic analysis of the effect of the microband electrode roughness on faradaic and capacitive responses, simulations of structures with different geometries (Fig. S6) were performed. The values of faradaic widths estimated by simulations and capacitive widths estimated by the length of the rough electrode boundary for different geometries of a microband electrode are summarized in Table 1. The small-scale roughness $(a=0.25 \mu \mathrm{m}$ and $a=0.5 \mu \mathrm{m}$; Fig. 5B and S7A-C) results in faradaic currents similar to those obtained at flat microband electrodes (Fig. 5A) regardless of the shape of the electrode profile. Interestingly, an enhancement of the faradaic currents was obtained at the geometries with bulgy large-scale sinusoidal roughness ( $a=2 \mu \mathrm{m}$; Fig. 5C) due to additional contribution to the diffusional flux from the lateral microelectrode surface created by bulging into the electrolyte. This effect was elucidated at the bulging rectangular microelectrode (Fig. 5D), as a limiting case for the number of periods, featured with equal values of faradaic and capacitive widths. On the other hand, the microelectrodes with recessed large-scale sinusoidal roughness ( $a=-2 \mu \mathrm{m}$; Fig. S8A) as well as the recessed rectangular microelectrodes (Fig. 5E) are characterized by a significant blocking of the diffusional flux by planar diffusion within the recessed area yielding current values close to the values obtained at the flat microelectrode.

The obtained results indicate a significant effect of the roughness scale and arrangement on the faradaic and capacitive EASAs. In general the capacitive EASA is more influenced by surface roughness than the faradaic EASA, in agreement with the experimental data. The faradaic responses at microband electrodes with bulging large scale roughness show an additional 
diffusional flux at the lateral surface of the microelectrode leading to an overestimation of the faradaic EASA compared to the data obtained analytically (eq. (7)). The recessed roughness of different scales yields a high reproducibility of the faradaic EASA but significant variations in capacitive EASA.

\section{Conclusions}

We have demonstrated, an influence of the electrode roughness and the concentration of the electrolyte solution on the capacitive EASA of microdisk electrodes and microband arrays of two different electrode materials. A dependence on measurement potential is also observed. The faradaic process utilized for the assessment of the EASA showed a higher reproducibility than the electrocapacitive measurements, which were affected by the surface roughness. Numerical modeling allowed a systematic analysis of the microband roughness effect on the interplay between faradaic and capacitive phenomena. Our findings manifest the need of consideration of roughness when calculating microelectrode surface areas for various applications. The EASA obtained from capacitive measurements should not be used to estimate the EASA for faradaic processes at surfaces with a non-negligible roughness.

\section{Conflict of interest}

The authors have no conflict of interest with any financial organization regarding the material discussed in the manuscript.

\section{Acknowledgments}

The authors acknowledge the funding provided by The Swedish research council Formas, the research center Security Link, The Swedish National Infrastructure for Computing at Linköping University for simulation resources and the Norrköpings fond för Forskning och Utveckling. 
A.V.V. and I.V.Z. would like to thank CeNano and the CeNano funded project "Simulation and modeling of nanoscaled porous membranes and electrodes". 


\section{References}

[1] K. Stulik, C. Amatore, K. Holub, V. Marecek, W. Kutner, Pure Appl. Chem. 2000, 72, 14831492.

[2] R.G. Compton, G.G. Wildgoose, N.V. Rees, I. Streeter, R. Baron, Chem. Phys. Lett. 2008, 459, $1-17$.

[3] R.O. Kadara, N. Jenkinson, C.E. Banks, Sensor. Actuat. B-Chem. 2009, 138, 556-562.

[4] R.M. Wightman, Science 2006, 311, 1570-1574.

[5] R.J. Forster, Chem. Soc. Rev. 1994, 23, 289-297.

[6] S. Trasatti, O.A. Petrii, Pure Appl. Chem. 1991, 63, 711-734.

[7] G. Jarzabek, Z. Borkowska, Electrochim. Acta 1997, 42, 2915-2918.

[8] J. Gala, A. Budniok, Surf. Technol. 1985, 24, 89-114.

[9] B.E. Conway, R.E. White, J.O.M. Bockris, Modern Aspects of Electrochemistry 16, Springer US1985.

[10] V. Fragkou, Y. Ge, G. Steiner, D. Freeman, N. Bartetzko, A.P.F. Turner, Int. J. Electrochem. Sci. 2012, 7, 6214-6220.

[11] J.D. Benck, Z. Chen, L.Y. Kuritzky, A.J. Forman, T.F. Jaramillo, ACS Catalysis, 2012, 2, 1916-1923.

[12] C.W. Li, J. Ciston, M.W. Kanan, Nature 2014, 508, 504-507.

[13] X.-J. Lv, G.-W. She, S.-X. Zhou, Y.-M. Li, RSC Advances 2013, 3, 21231-21236.

[14] A.A. Kornyshev, J. Phys. Chem. B 2007, 111, 5545-5557.

[15] A.C. Maggs, R. Podgornik, Soft Matter 2016, 12, 1219-1229

[16] K. Aoki, J. Osteryoung, J. Electroanal. Chem. 1981, 122, 19-35.

[17] K. Aoki, K. Tokuda, H. Matsuda, J. Electroanal. Chem. 1987, 230, 61-67. 
[18] R.M. Wightman, D.O. Wipf, Electroanalytical Chemistry, in: A.J. Bard (Ed.), M. Dekker, Inc., New York, 1989.

[19] K. Aoki, C. Ouyang, C. Zhang, J. Chen, T. Nishiumi, Int. J. Electrochem. Sci. 2012, 7, 58805892.

[20] Y. Saito, Review of Polarography 1968, 15, 177-187.

[21] Z. Porat, J.C. Crooker, Y.N. Zhang, Y. LeMest, R.W. Murray, Anal. Chem. 1997, 69, 50735081.

[22] A.J. Bard, L.R. Faulkner, Electrochemical Methods. Fundamentals and Applications, 2 ed., John Wiley \& Sons, Inc2001.

[23] S.L. Caston, R.L. McCarley, J. Electroanal. Chem. 2002, 529, 124-134.

[24] M.Y. Vagin, A.N. Sekretaryova, R.R. Sanchez, I. Lundstrom, F. Winquist, M. Eriksson, ChemElectroChem 2014, 1, 755-762.

[25] A.N. Sekretaryova, A.V. Volkov, I.V. Zozoulenko, A.P.F. Turner, M.Y. Vagin, M. Eriksson, Anal. Chim. Acta 2016, 907, 45-53.

[26] C. Amatore, J.M. Saveant, D. Tessier, J. Electroanal. Chem. 1983, 147, 39-51.

[27] S.J. Konopka, B. McDuffie, Anal. Chem. 1970, 42, 1741-1746.

[28] R.M. Penner, C.R. Martin, Anal. Chem. 1987, 59, 2625-2630.

[29] D.C. Grahame, Chem. Rev. 1947, 41, 441-501.

[30] R.T. Carvalhal, R.S. Freire, L.T. Kubota, Electroanal. 2005, 17, 1251-1259.

[31] H. Boo, S. Park, B.Y. Ku, Y. Kim, J.H. Park, H.C. Kim, T.D. Chung, JACS 2004, 126, 45244525.

[32] D. Menshykau, X.-J. Huang, N.V. Rees, F.J. del Campo, X.F. Munoz, R.G. Compton, Analyst 2009, 134, 343-348.

[33] D. Menshykau, I. Streeter, R.G. Compton, J. Phys. Chem. C 2008, 112, 14428-14438. 
Table 1. Comparison between the faradaic and capacitive widths for microband electrodes of different geometries.

\begin{tabular}{|c|c|c|c|c|c|}
\hline \multirow[b]{2}{*}{ Geometry } & \multirow{2}{*}{$\begin{array}{l}\text { Scale of roughness, } \\
\qquad \mu \mathrm{m}\end{array}$} & \multirow{2}{*}{$\begin{array}{l}\text { Modelling } \\
\text { function }\end{array}$} & \multicolumn{2}{|c|}{ Width } & \multirow{2}{*}{$\begin{array}{c}\text { Faradaic-to-capacitive } \\
\text { ratio }\end{array}$} \\
\hline & & & faradaic, $\mu \mathrm{m}$ & capacitive, $\mu \mathrm{m}$ & \\
\hline \multicolumn{3}{|l|}{ Flat } & 7.01 & 7 & 1.001 \\
\hline \multirow{4}{*}{ Small-scale roughness } & \multirow{2}{*}{0.25} & cosine & 7.23 & 7.522 & 0.961 \\
\hline & & sine & 7.22 & 8.849 & 0.816 \\
\hline & \multirow{2}{*}{0.5} & cosine & 7.61 & 8.849 & 0.860 \\
\hline & & sine & 7.63 & 12.642 & 0.604 \\
\hline \multirow{3}{*}{ Large-scale roughness } & \multirow{3}{*}{2} & cosine & 10.19 & 21.675 & 0.470 \\
\hline & & sine & 10.22 & 41.011 & 0.249 \\
\hline & & cosine, recessed & 6.97 & 21.675 & 0.322 \\
\hline \multicolumn{3}{|l|}{ Rectangular recessed } & 8.39 & 11 & 0.763 \\
\hline \multicolumn{3}{|l|}{ Rectangular bulgy } & 11.1 & 11 & 1.009 \\
\hline
\end{tabular}




\section{Figure legends}

Figure 1. Microband electrode. A: The layout of the screen-printed array of graphite microband electrodes; B: A 2D 'slice' of a microband used as the simulation domain.

Figure 2. Surface area estimation from capacitive currents. Cyclic voltammograms recorded in 1 $\mathrm{M} \mathrm{HCl}$ with different scan rates: $10 \mathrm{mV} / \mathrm{s}, 20 \mathrm{mV} / \mathrm{s}, 50 \mathrm{mV} / \mathrm{s}, 80 \mathrm{mV} / \mathrm{s}, 100 \mathrm{mV} / \mathrm{s}$ and $200 \mathrm{mV} / \mathrm{s}$ of $\mathbf{A}$ : the graphite microband array (10 microbands, each with $1.5 \mathrm{~mm}$ length and $7 \pm 1 \mu \mathrm{m}$ width) and B: the graphite disk electrode (diam. $1.8 \mathrm{~mm}$ ). C and D: Dependence of the capacitive currents measured at $0.15 \mathrm{~V}$ on the scan rate for the microband array and the graphite disk electrode, respectively.

Figure 3. Surface area estimation by faradaic currents. A: Chronoamperograms of $1 \mathrm{mM}$ $\mathrm{K}_{4} \mathrm{Fe}(\mathrm{CN})_{6}$ in $1 \mathrm{M} \mathrm{HCl}$ oxidation at screen-printed microband arrays with different microband length for a potential step from 0 to $0.6 \mathrm{~V}$. The numbers indicate microband length in $\mathrm{mm}$ multiplied by 10 (the number of microbands in the array). B: Comparison of experimental (solid lines) and simulated (dotted lines) chronoamperograms (potential step from 0 to $0.6 \mathrm{~V}$ ). Extrapolations of the linear part of the experimental curves (black dashed lines) are shown. Simulated curves were obtained by numerical (cyan and magenta dotted lines for flat and rough $\left(z=a \cos ^{2}(\pi b y / w), a=0.5 \mu \mathrm{m}, b=5\right)$ microband electrodes, respectively) and analytical calculations ( $\square$; eq. 7)

Figure 4. Capacitive $v s$ faradaic EASA. The data are represented by mean value and error bars for 5 samples with Student's t-distribution at 95\% confidence. A: Screen-printed carbon microband arrays for faradaic $(\boldsymbol{\square})$, capacitive $(\boldsymbol{\Delta})$ and geometric $(\circ)$ measurements. The three different types of data at each microband length have been slightly displaced laterally for clarity. B and C: AuME in $10 \mathrm{mM} \mathrm{KNO}_{3}$ and in $1 \mathrm{M} \mathrm{KNO}_{3}$, respectively. The dashed lines are the geometric surface area $\left(1.2 \times 10^{-6} \mathrm{~cm}^{2}\right)$.

Figure 5. Simulated reactant concentration profiles obtained in the diffusion limited regime at a cross-section of microbands of different geometries. A - flat; $\mathbf{B}$ and $\mathbf{C}$ - small $(0.25 \mu \mathrm{m})$ and large 
$(2 \mu \mathrm{m})$ scale squared cosine roughness, respectively; $\mathbf{D}$ and $\mathbf{E}$ - bulging and recessed rectangular geometries, respectively. 

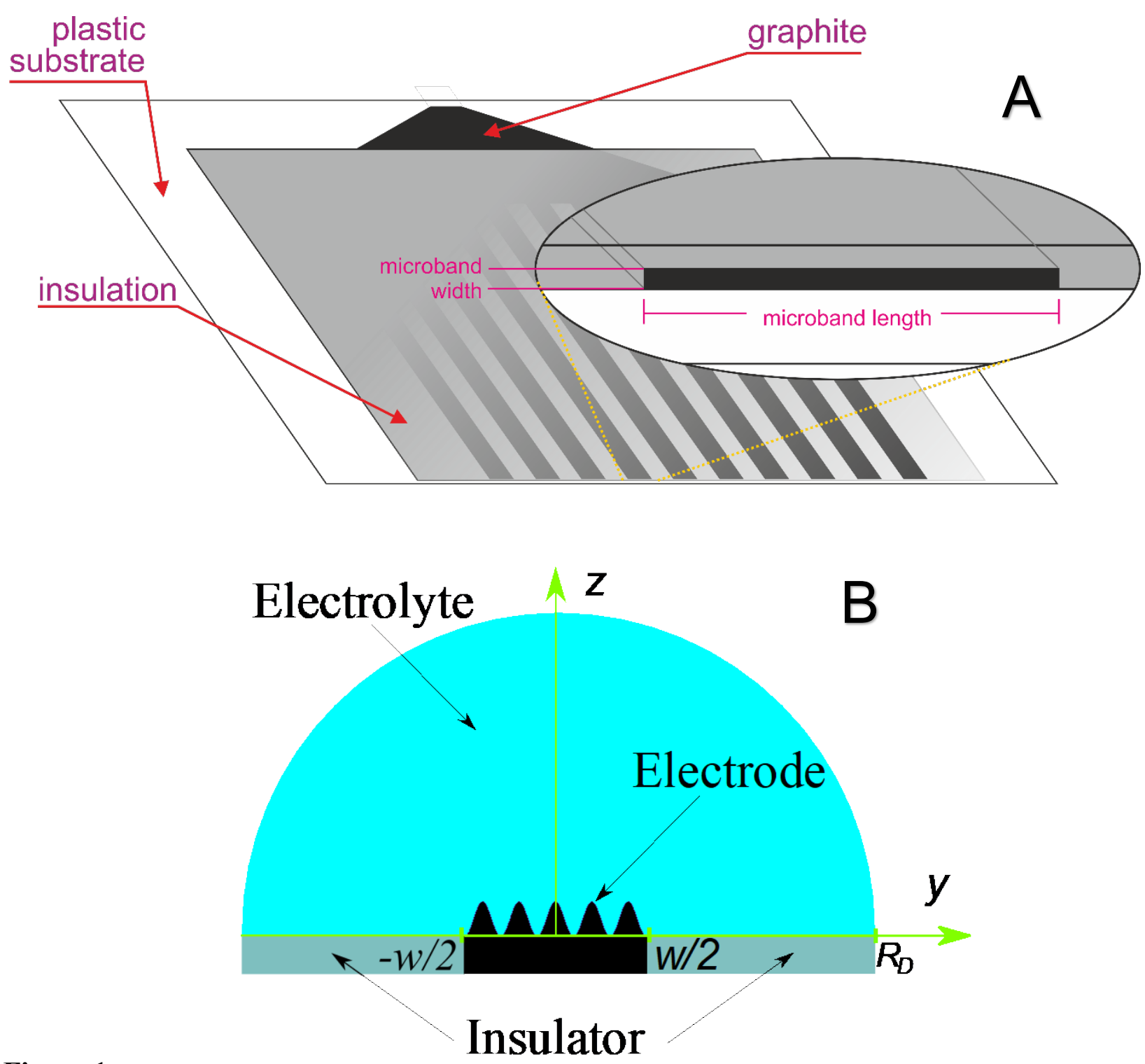

Figure 1. 

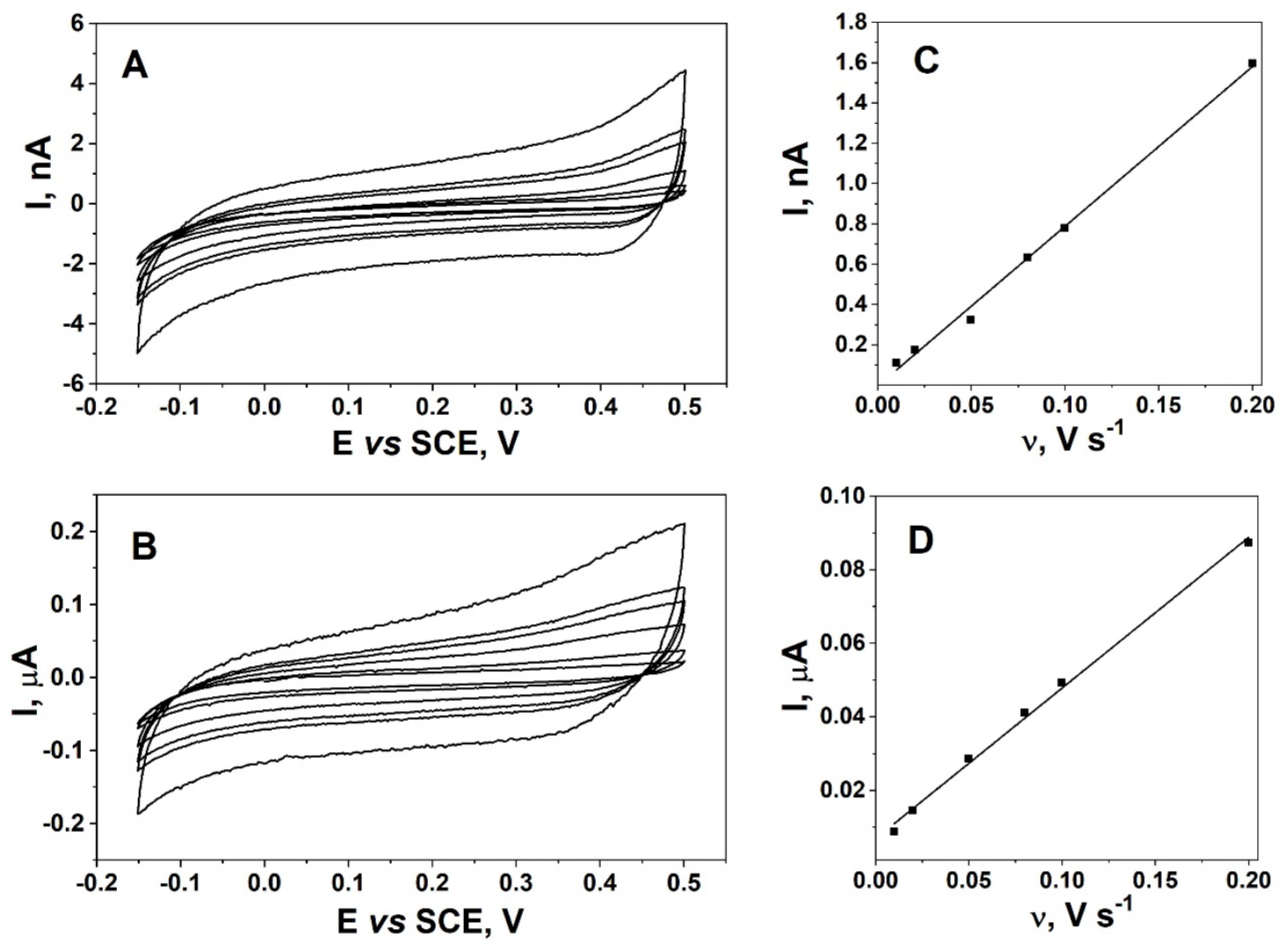

Figure 2. 

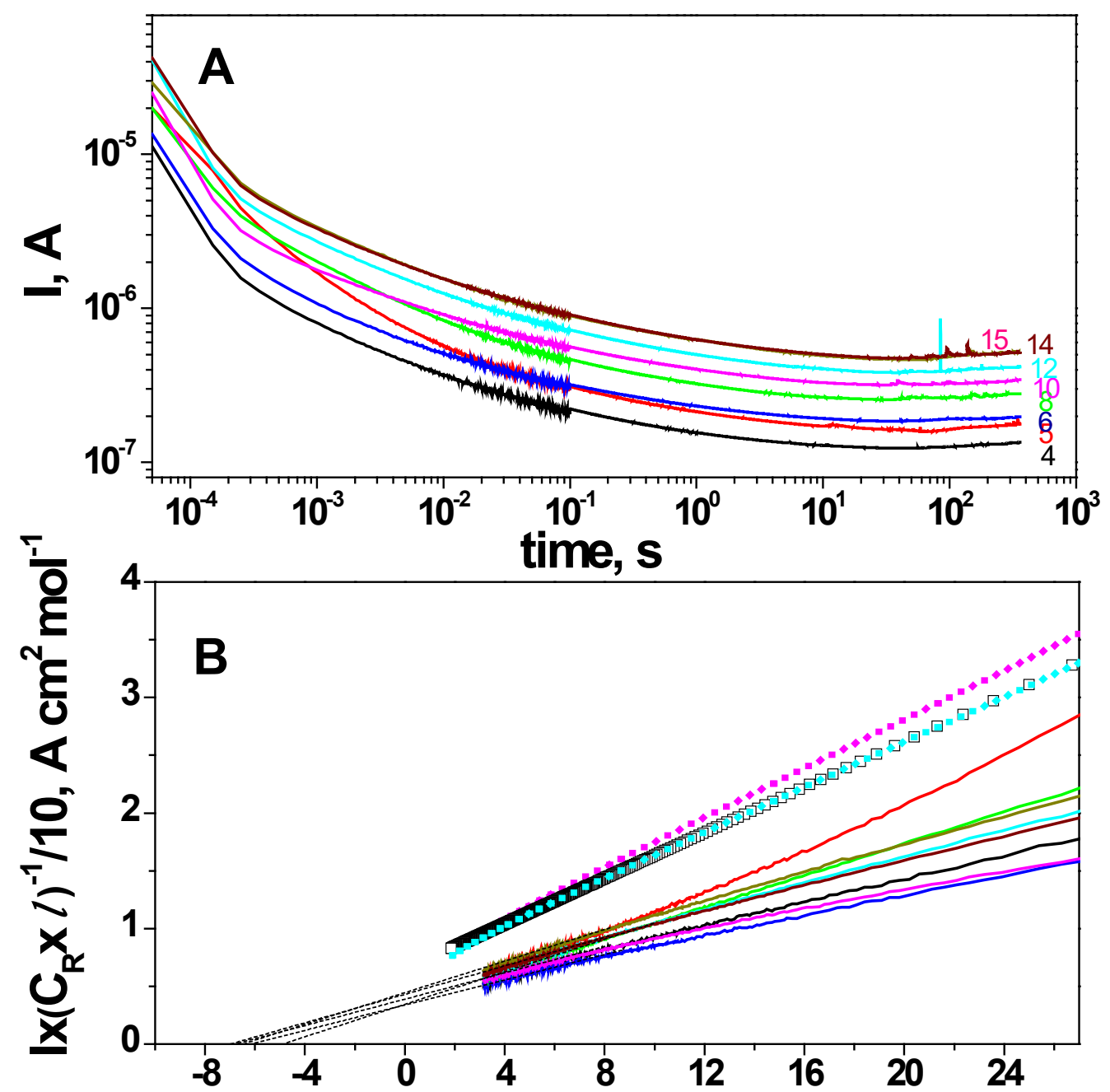

(time, s) ${ }^{-1 / 2}$

Figure 3. 

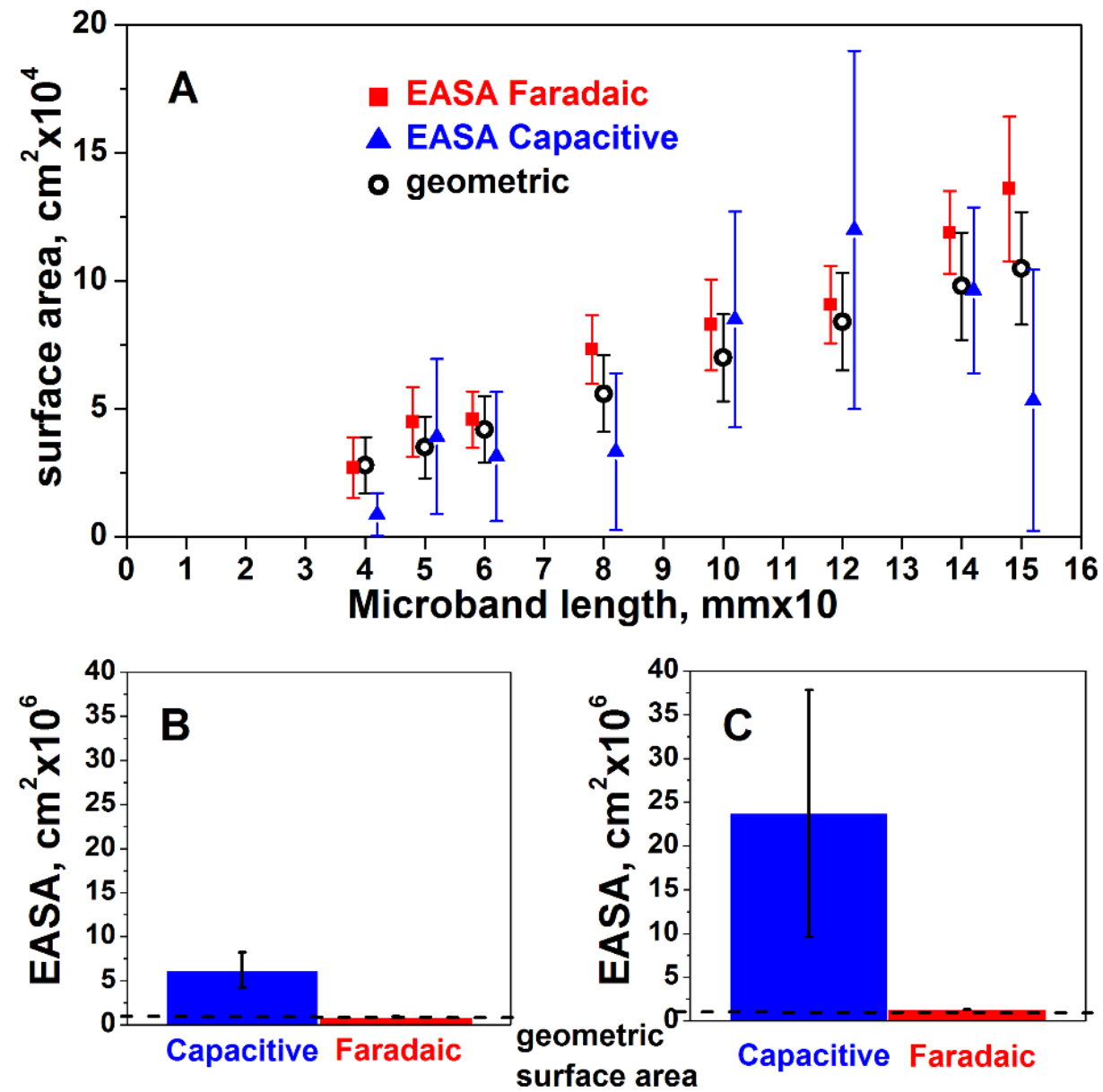

Figure 4. 


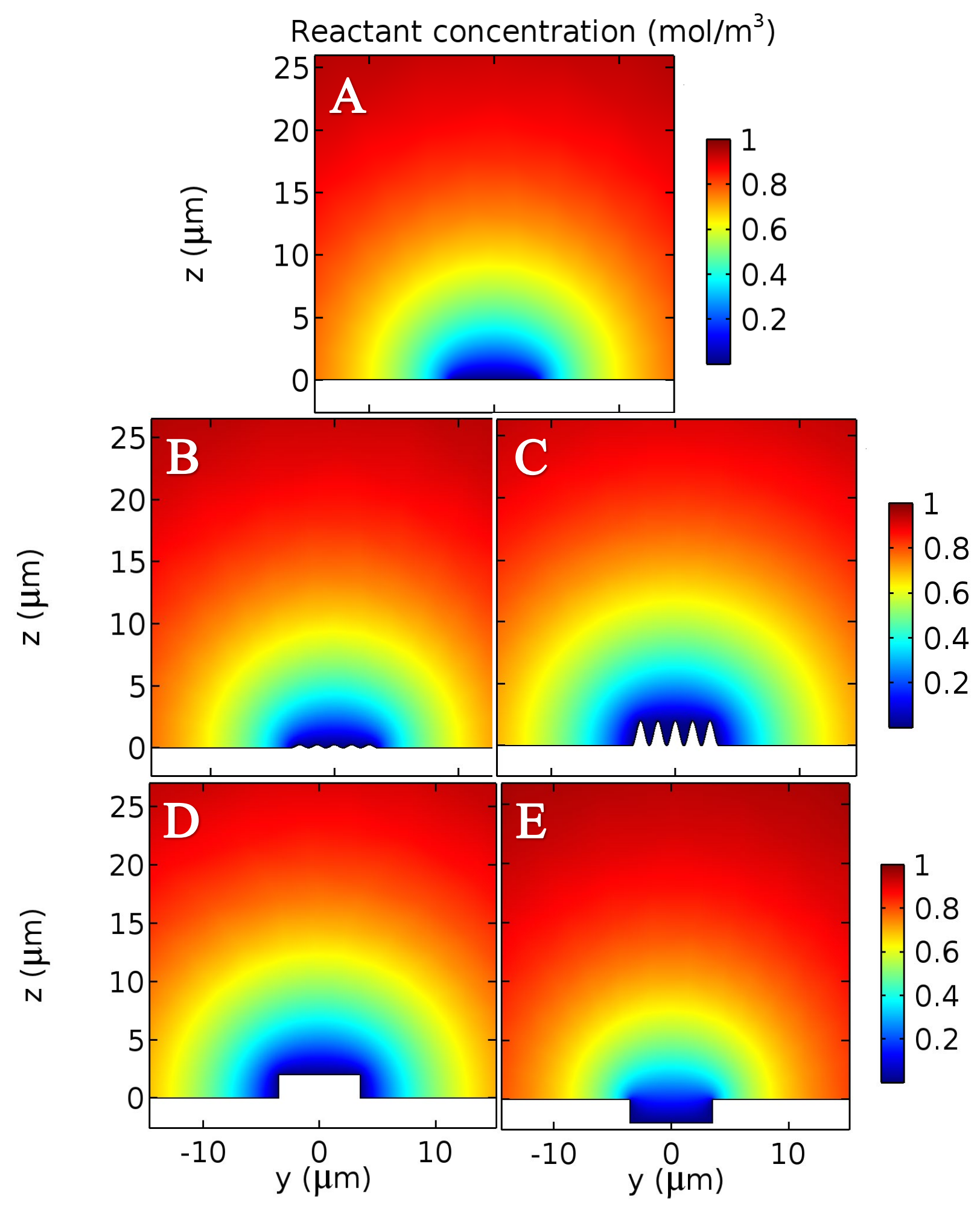

Figure 5. 


\section{Table of Contents}

The faradaic process used for the estimation of the electrochemically active surface area of microelectrodes showed a higher reproducibility than the electrocapacitive process affected by the surface roughness. Numerical modeling allowed a systematic evaluation of the roughness effect on the faradaic and capacitive

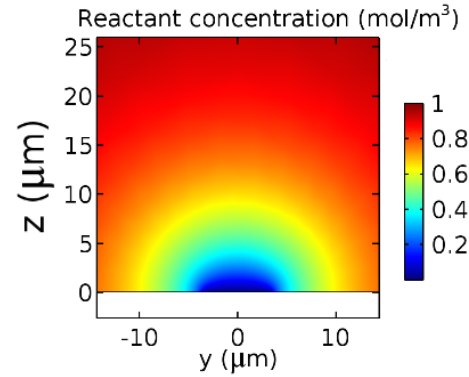
phenomena. 


\section{SUPPORTING INFORMATION}

\section{Evaluation of the electrochemically active surface area of microelectrodes by capacitive and faradaic currents}

Alina N. Sekretaryova ${ }^{1,2}$, Mikhail Yu. Vagin ${ }^{1,3^{*}}$, Anton V. Volkov ${ }^{3}$, Igor V. Zozoulenko ${ }^{3}$, Mats Eriksson $^{1}$

${ }^{1}$ Department of Physics, Chemistry and Biology, Linköping University, SE-581 83, Linköping, Sweden

${ }^{2}$ Department of Chemistry - Ångström, Uppsala University, Lägerhyddsvägen 1, 75120, Uppsala, Sweden

${ }^{3}$ Laboratory of Organic Electronics, Department of Science and Technology, Linköping University, SE-601 74, Norrköping, Sweden

*Corresponding author

Mikhail Yu. Vagin

Email: mikhail.vagin@liu.se

Phone: $+46(0) 702753087$ 


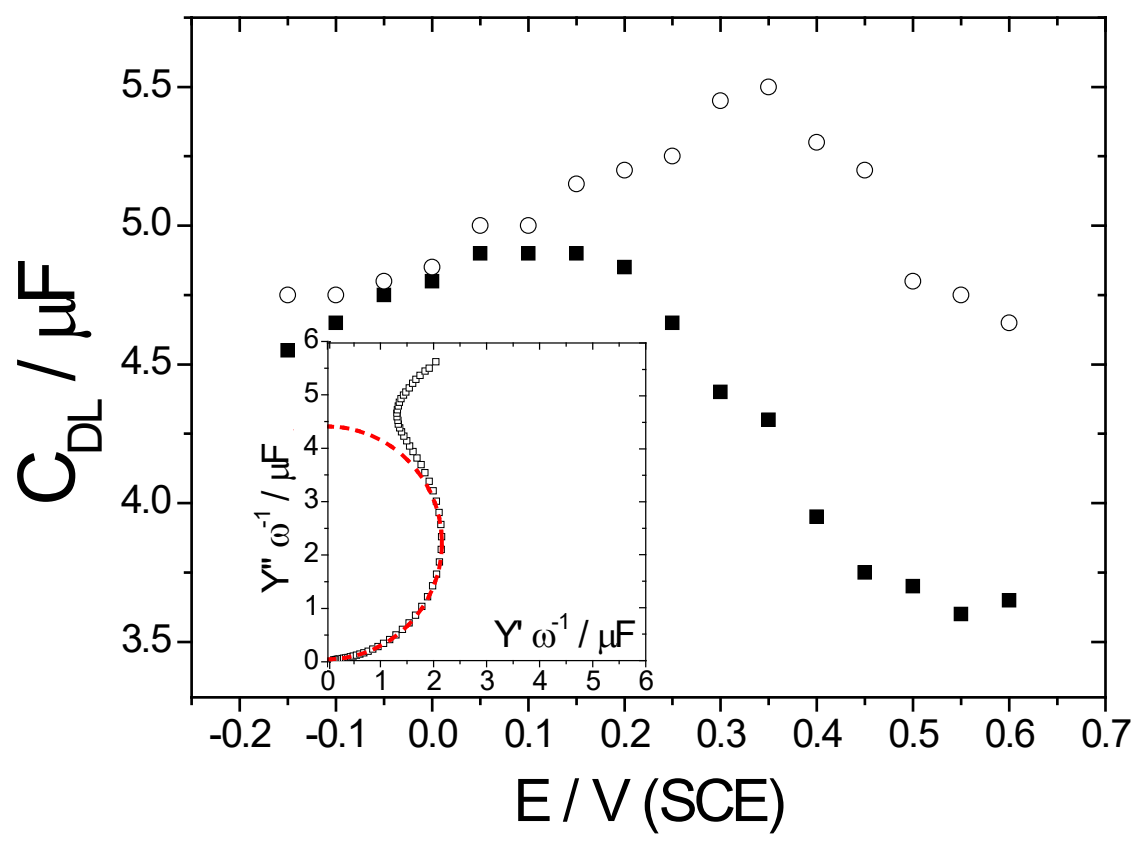

Figure S1. The potential dependence of the double layer capacitance of the screen-printed macroelectrode in concentrated $(1 \mathrm{M} \mathrm{HCl}, \bigcirc)$ and diluted $(0.5 \mathrm{mM} \mathrm{HCl}, \mathbf{\square})$ electrolyte solutions. Inset: the impedance spectrum in complex capacitance coordinates $(0.5 \mathrm{mM} \mathrm{HCl}, 0.3 \mathrm{~V}$ vs $\mathrm{SCE})$. 


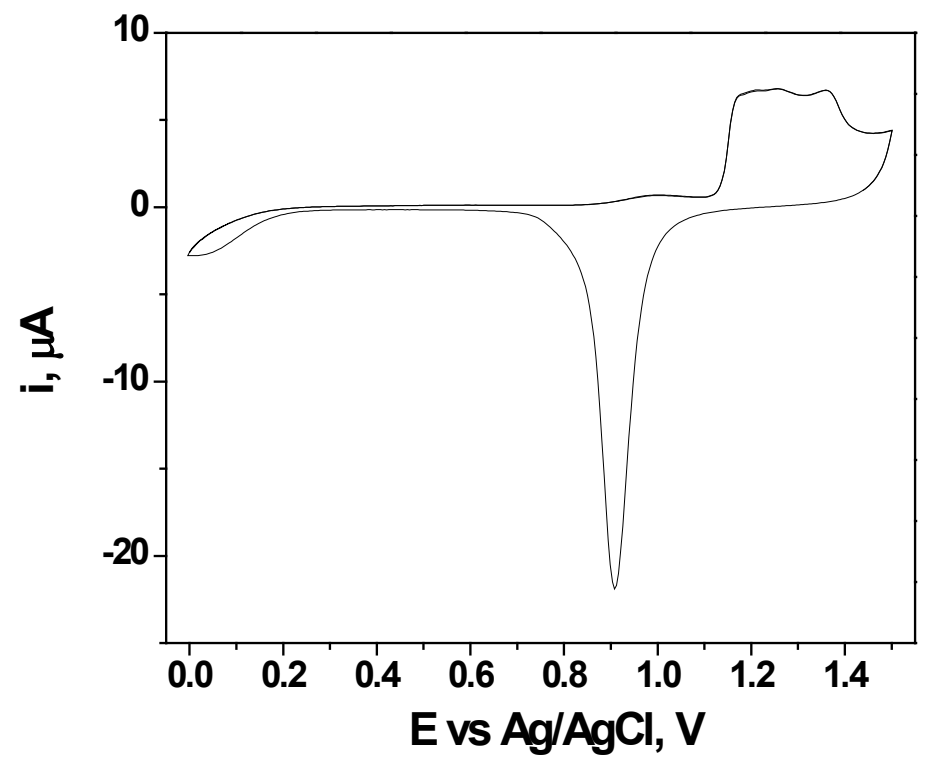

Figure S2. Cyclic voltammogram of the gold disk macroelectrode (diam. $2 \mathrm{~mm}$ ) in $0.5 \mathrm{M}$ $\mathrm{H}_{2} \mathrm{SO}_{4}$, scan rate $100 \mathrm{mV} \mathrm{s}^{-1}$. 

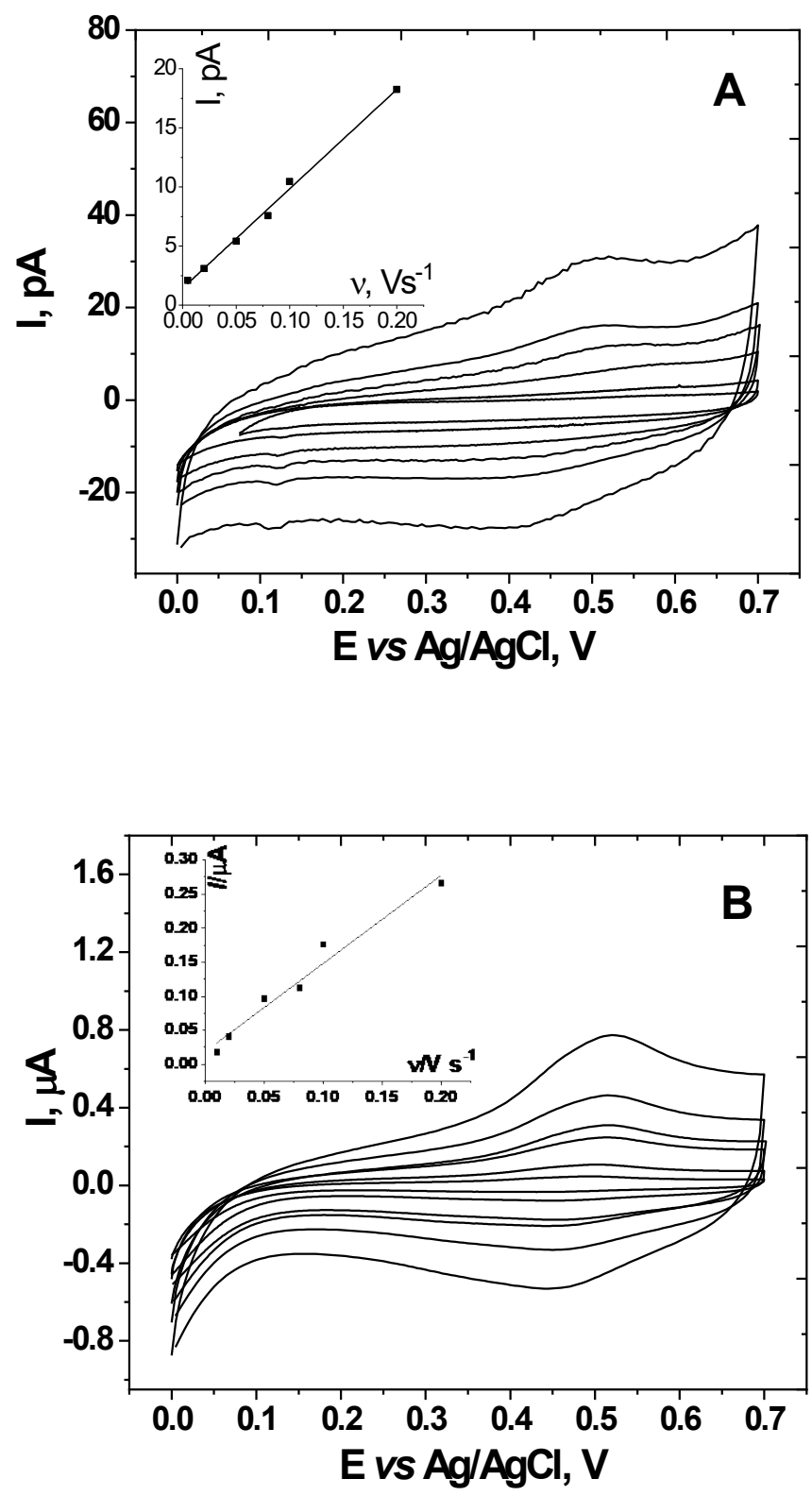

Figure S3. Estimation of the EASA of an AuME (A, diam. $12.5 \mu \mathrm{m})$ and a gold disk electrode (B, diam. $2 \mathrm{~mm}$ ) by capacitive currents in $10 \mathrm{mM} \mathrm{KNO}_{3}$. Cyclic voltammograms recorded with scan rates: $10 \mathrm{mV} / \mathrm{s}, 20 \mathrm{mV} / \mathrm{s}, 50 \mathrm{mV} / \mathrm{s}, 80 \mathrm{mV} / \mathrm{s}, 100 \mathrm{mV} / \mathrm{s}$ and $200 \mathrm{mV} / \mathrm{s}$. Insets: Dependence of the capacitive currents measured at $0.2 \mathrm{~V}$ on scan rate. 

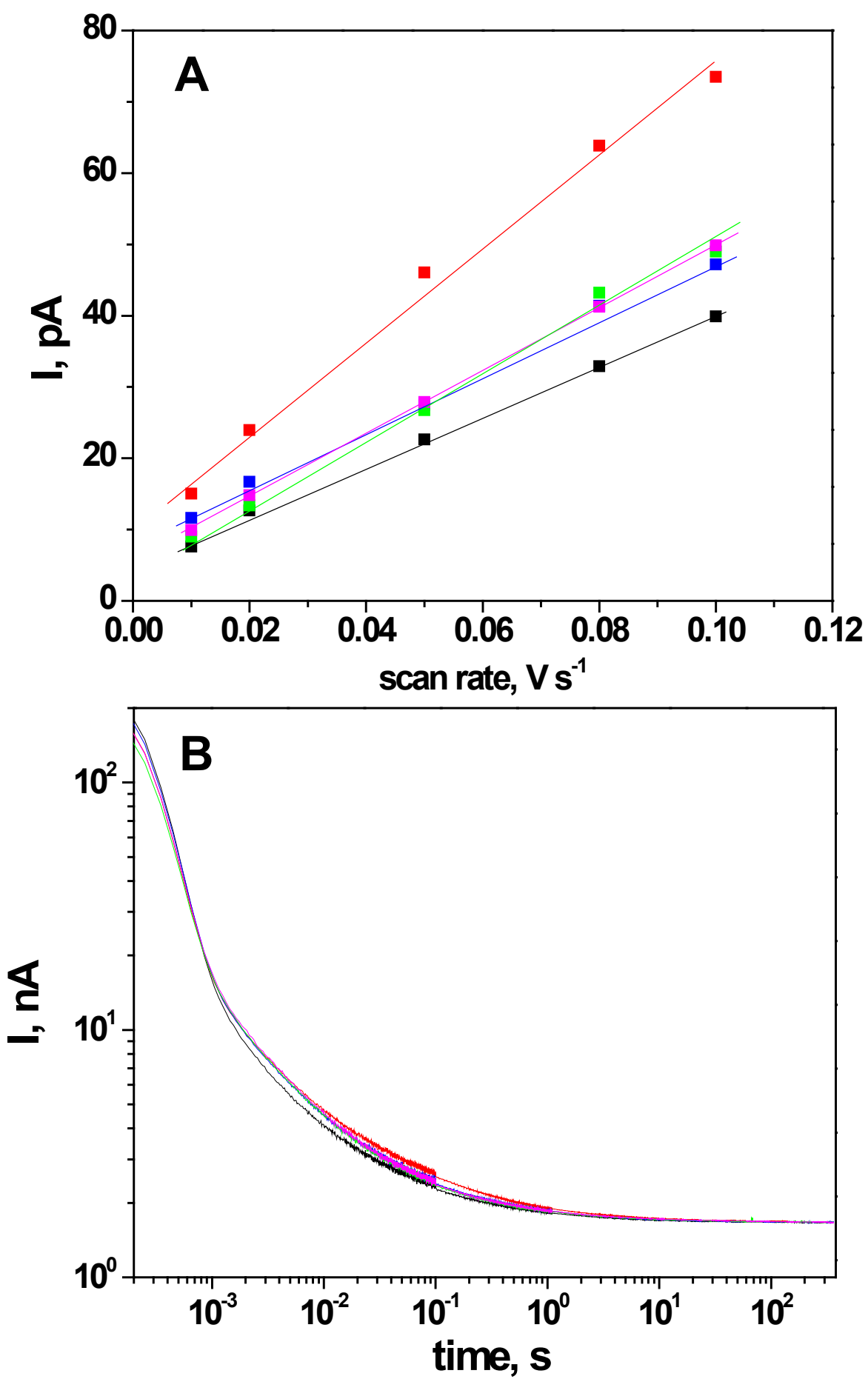

Figure S4. Capacitive and faradaic response at the AuME (diam. $12.5 \mu \mathrm{m}$ ) with different roughnesses (indicated by different colors). A: Dependences of capacitive currents measured by cyclic voltammetry at AuMEs of different roughness $\left(0.2 \mathrm{~V}, 1 \mathrm{M} \mathrm{KNO}_{3}\right.$, scan rates: $10 \mathrm{mV} / \mathrm{s}, 20$ $\mathrm{mV} / \mathrm{s}, 50 \mathrm{mV} / \mathrm{s}, 80 \mathrm{mV} / \mathrm{s}, 100 \mathrm{mV} / \mathrm{s}$ ); B: Chronoamperograms of ferrocyanide oxidation, $1 \mathrm{mM}$ solution of $\mathrm{K}_{4} \mathrm{Fe}(\mathrm{CN})_{6}$ in $1 \mathrm{M} \mathrm{KNO}_{3}$, potential step from 0 to $0.6 \mathrm{~V}$. 

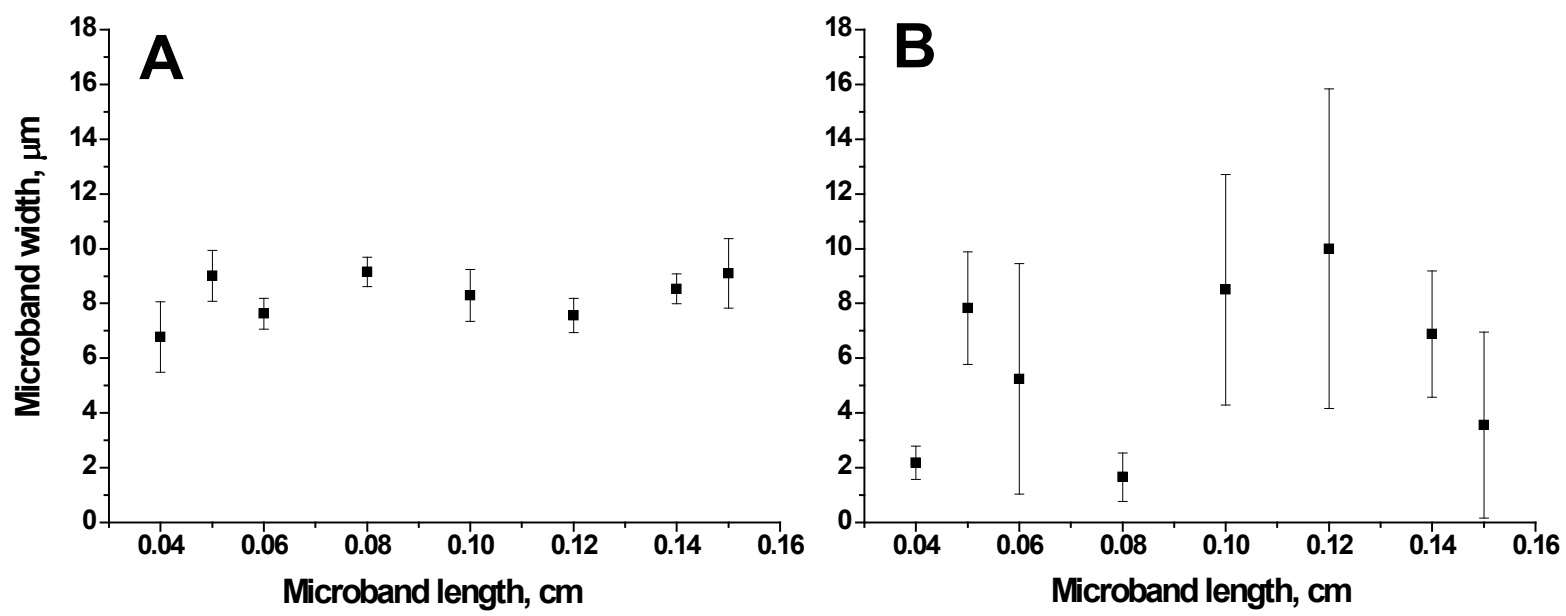

Figure S5. The microband width dependence on microband length obtained from faradaic (A) and capacitive (B) measurements of graphite microband arrays. 


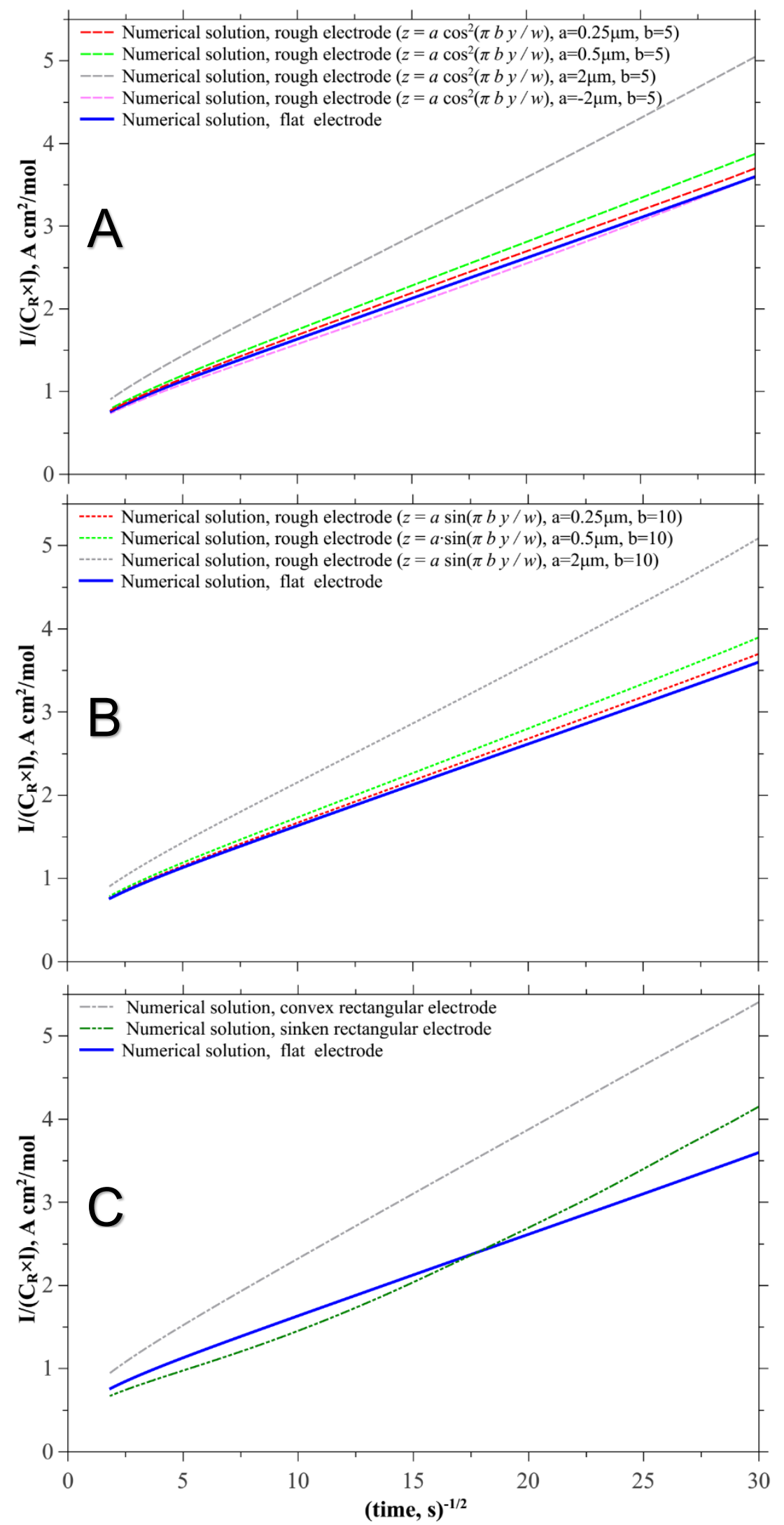

Figure S6. Comparison of simulated chronoamperograms obtained for flat (solid blue curves) and rough microband electrodes (dashed curves). The electrode boundary is defined by squared cosine (A) or sine (B) functions with recessed and bulging roughness of different scale; C: Simulated chronoamperograms of recessed and bulging rectangular microbands. 


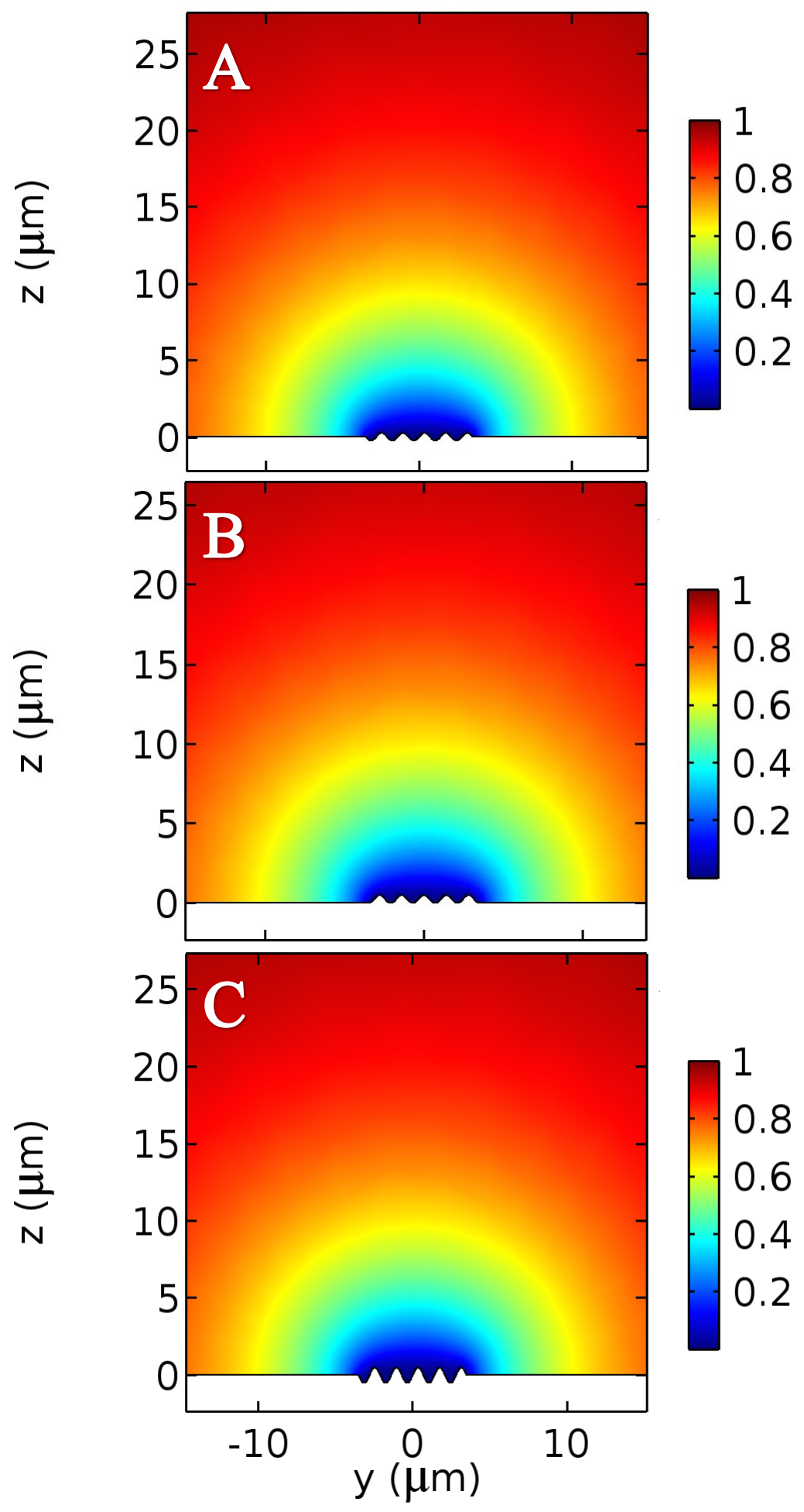

Figure S7. Reactant concentration profiles obtained in the diffusion limited regime at a crosssection of small scale roughness (A $0.25 \mu \mathrm{m}$; B and $\mathbf{C}: 0.5 \mu \mathrm{m})$ microband electrodes. Electrode boundaries were modelled by squared cosine (B) and sine (A and $\mathbf{C})$ functions. 


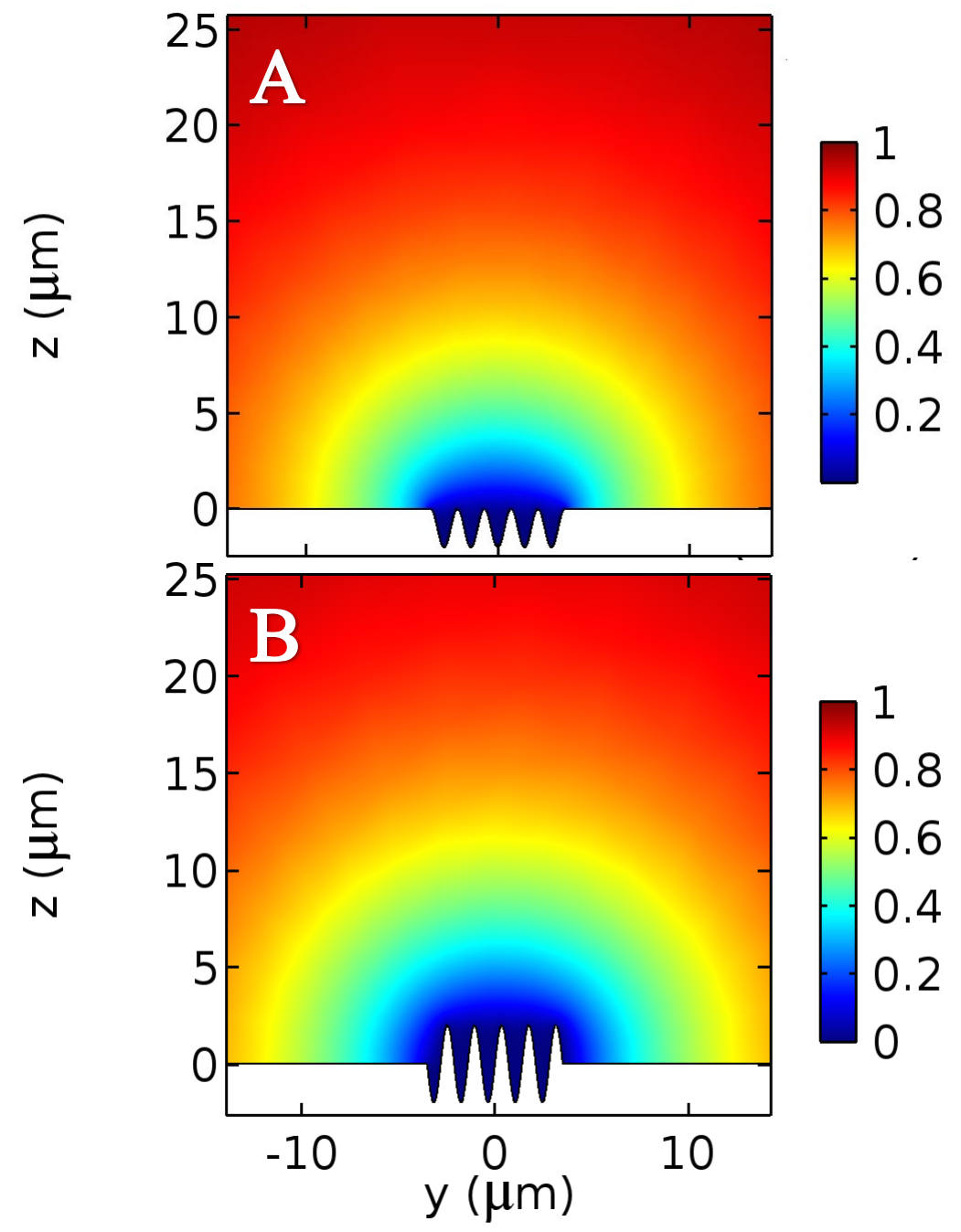

Figure S8. Reactant concentration profiles obtained in the diffusion limited regime at a crosssection of the microband electrodes with large scale roughness $(2 \mu \mathrm{m})$. Electrode boundaries were modelled by recessed, squared cosine (A) and sine (B) functions. 